\title{
THE ROLE OF SCHOOLS IN SHAPING THE SETTLEMENT EXPERIENCES OF NEWCOMER IMMIGRANT AND REFUGEE YOUTH
}

\section{Erwin Dimitri Selimos and Yvette Daniel}

\begin{abstract}
This paper draws on focus groups and interviews with newcomer immigrant and refugee youth between the ages of 16 and 22 to consider how schools shape their settlement processes and their sense of social inclusion and belonging. In particular, the paper focuses on newcomer youth's perspectives and experiences of schooling in a medium-sized immigrant-receiving city in Canada. Analysis reveals that schools function as sites of both inclusion and exclusion in ways that produce ambivalence in immigrant and refugee youth with respect to their sense of social inclusion and belonging to community life. One recommendation emerging from the analysis is that educational practitioners and other community stakeholders interested in supporting the social inclusion of newcomer youth should develop and implement ESL and ELD programs and ensure adequate funding of these essential programs. There is also a need for collaborative, dialogical practices that provide all relevant stakeholders, including newcomer youth themselves, opportunities to come together to create new possibilities for understanding and cooperative action.
\end{abstract}

Keywords: newcomer immigrant and refugee youth, schools, settlement, social inclusion and exclusion

Erwin Dimitri Selimos PhD (corresponding author) is a Postdoctoral Fellow in the Department of Sociology, University of Alberta, 116 St. and 85 Ave., Edmonton, AB T6G 2R3. Email: selimos@ualberta.ca

Yvette Daniel PhD is Associate Professor of Educational Administration and Policy Studies, Faculty of Education, University of Windsor, 401 Sunset Ave, Windsor, ON N9B 3P4. 
Countries that receive young migrants, including Canada, are faced with the challenges of integrating these populations socially, culturally, and economically. In Canada, as well as internationally, there has been increased focus on local community capacity to enhance the social inclusion of immigrants and refugees (George, Selimos, \& Ku, 2017); United Nations Educational, Scientific, and Cultural Organization, 2016). Given this reality, there is a need to explore the effectiveness of community services that support the social inclusion of young migrants in order to design better service provisions and supports. While some research has focused on how communities cultivate and enhance immigrant inclusion (George et al., 2017), less research has considered how immigrant and refugee youth experience the practices that aim to support their settlement (Ngo, 2009).

Schools are central institutions of community life and play a critical role in the social inclusion of newcomer immigrant and refugee youth (Brewers \& McCabe, 2014; Devine, 2011; LeVasseur, 2008). In fact, the importance of schooling to the social inclusion of newcomer youth can be seen in both Canadian studies (Anisef \& Kilbride, 2003; Garnett, Adamuti-Trache, \& Ungerleider, 2008; Krahn \& Taylor, 2005; Sweet, Anisef, \& Walters, 2010; Wilkinson, Yan, Ka Tat Tsang, Sin, \& Lauer, 2011) and international studies (Devine, 2011; Fangen, Johansson, \& Hammaren, 2012) that examine immigrant youths' educational challenges, needs, and outcomes. However, research rarely situates newcomer youths' schooling experiences within the larger community context in which their settlement and inclusion unfolds. Any consideration of how communities can support the settlement of newcomer youth must consider how schools shape their social inclusion processes within community life.

Drawing on focus groups and semi-structured interviews conducted with newcomer youth, this paper explores their experiences of schooling in a medium-sized immigrant-receiving city in Ontario, Canada. In particular, it contributes to international and Canadian literature on migrant youth inclusion by exploring how newcomer youths' sense of social inclusion and belonging to community life is shaped by schools. The paper is guided by three main questions:

- How do schools attempt to facilitate the settlement and social inclusion of newcomer immigrant and refugee youth?

- How do newcomer youth experience their education and schooling within this institutional framework?

- What effects, if any, do schools have on young immigrants' and refugees' sense of identity, social inclusion, and belonging to community life?

Our analysis shows that schools function simultaneously as sites of social inclusion and exclusion. The placement of newcomer youth into specific "immigrant-receiving schools", as well as their placement into distinct language-learning classes within those schools, tends to segregate them from other youth. The effect is to create spaces of inclusion and belonging within the school and community (places newcomer youth can come together), while simultaneously engendering 
International Journal of Child, Youth and Family Studies (2017) 8(2): 90-109

their exclusion from what many participants referred to as "real Canadians". This semipermeable and dynamic social segregation produces feelings of support, inclusion, and belonging, but these are made ambivalent by concurrent feelings of stigmatization and marginality.

\section{Newcomer Youth, Social Inclusion and Exclusion, and Schools}

Settlement is defined here as the long-term, dynamic process through which immigrants attempt to achieve full participation in various domains of social life in the society of permanent residence (Murphy, 2010, p. 11). In this sense, settlement presumes processes of social exclusion and inclusion. Social exclusion refers to the process by which individuals and groups are disconnected from social relations and institutions (Silver, 2007). At the level of social participation, social exclusion includes being denied access or confronted with barriers to participation in the various institutions of society, including education, the labour market, community life, and political decision-making. At the symbolic level, social exclusion is expressed through experiences of being disrespected, and marked as different in derogatory ways (Fangen et al., 2012, pp. 7 \& 10). Davis and Hill (2006) note that the nature of our social relations can also serve to integrate people into support networks and social and economic institutions (p. 4). Social inclusion can be thought of as a process of building social connections, participating in social institutions, and being recognized as a rightful member of a community.

The social exclusion of immigrant and refugee youth is well documented internationally in research showing that migrant youth are systematically denied access to and participation in education, the labour market, the political system, and even some public spaces (Fangen et al., 2012). Canadian scholarship discusses the various barriers newcomer youth face to social, economic, and political inclusion, such as: the challenges and difficulties of learning English (Anisef \& Kilbride, 2003); limited services and resources (Francis \& Yan, 2016; Walsh, Este, Krieg, \& Giurgiu, 2011); discrimination (Shahsiah, 2006; Tomic, 2012); peer victimization and bullying (McKenney, Pepler, Craig, \& Connolly, 2006); and multifaceted barriers to labour market participation (Lauer, Wilkinson, Yan, Sin, \& Ka Tat Tsang, 2012; Taylor \& Krahn, 2013; Wilkinson et al., 2011).

When newcomer youth settle in a new community, they are often circumscribed by their dual status as both young people and new immigrants. They often lack social connections and knowledge of their new communities of residence; schools are the main institutions where they develop this cultural knowledge, build social connections, acquire social capital, and begin to participate in their communities (Brewers \& McCabe, 2014). In school, newcomer youth are socialized into the norms of the host society, are offered specific targeted supports, such as language training and work experience programmes, and find avenues to participation in community life through volunteer opportunities, field trips, and extracurricular activities.

The importance of schools to the social inclusion of immigrant and refugee youth is reflected in the many Canadian studies that examine their educational experiences and educational outcomes (Anisef \& Kilbride, 2003; Garnett et al., 2008; Hebert, Sun, \& Kwoch, 2004; Krahn \& 
International Journal of Child, Youth and Family Studies (2017) 8(2): 90-109

Taylor, 2005; Sweet et al., 2010; Wilkinson et al., 2011; Wilkinson, 2002) and their educational concerns and struggles (Kanu, 2008; Ngo \& Schliefer, 2005). Overall, these studies detail the factors that hinder immigrant and refugee youths' educational achievement, including lack of familiarity with schooling norms in the host society, lack of access to adequate English as a second language instruction, racism and discrimination, peer exclusion and bullying, and limited participation in school activities (see Ngo \& Schleifer, 2005 for a detailed summary).

However, the learning that happens in schools must be conceived more broadly than simply the development of skills, language proficiencies, academic knowedge, or the opportunity to participate in the larger society. As Devine (2011, p. 133) reminded us, schooling involves a process of subjectification in which young people come to understand their relations to other people and their position within the social order (see also Lave \& Wenger, 1991; Willis, 1977). Overt administrative and pedagogical practices (e.g., specialization and differentiation among schools, course streaming, and classroom teaching) and covert practices (rituals, routines, and social relations) tacitly communicate values, beliefs, and norms to young people, including newcomer youth, in ways that position them "in relation to a number of identity constructs and classificatory systems" (Hall, 2002, p. 89). Through these practices, schools intentionally or unintentionally impose conditions on young people's possibilities and pathways for establishing relations with others (see Sedano, 2012, p. 383). In this way, schools help produce subjectivity among those defined as "normal" or as "different" (Hall, 2002, p. 89).

\section{The City and its Architecture of Educational Supports for Newcomer Youth}

This research took place in a medium-sized, immigrant-receiving city in Ontario, Canada. In recent years, the city has experienced significant economic issues, including high levels of unemployment, due to the decline of the auto-manufacturing industry in North America. The city has a rich cultural and migratory history, including First Nations people, English and French colonization, and waves of European immigrant settlement, including Italians, Greeks, Eastern Europeans, and Middle Eastern immigrants from Lebanon, producing a layered ethnocultural diversity made even more complex by the continual arrival of new immigrants. In fact, despite its economic struggles, the city remains an important immigrant destination in Ontario, especially among those outside the Greater Toronto Area, and is exemplary of multicultural Canada.

The city's migration history and continuing role as an immigrant destination site has led to the development of a robust infrastructure to help with the settlement of newcomer immigrants. Seven main agencies provide settlement services, which include language classes, orientation and citizenship programs, and employment assistance. Settlement agencies throughout the city offer programs specifically targeting newcomer youth, including homework support, access to computers and the internet, employment help, counselling services, and extracurricular activities such as drumming circles, art classes, and field trips. 
International Journal of Child, Youth and Family Studies (2017) 8(2): 90-109

Table 1 Student population characteristics by high school

\begin{tabular}{|c|c|c|c|c|c|c|c|c|c|c|c|c|c|c|c|c|c|c|c|}
\hline \multirow{2}{*}{$\begin{array}{c}\text { Population } \\
\text { Characteristics }\end{array}$} & \multirow{2}{*}{$\begin{array}{c}\text { Provincial } \\
\text { Average } \\
(\%) \\
\end{array}$} & \multicolumn{18}{|c|}{ Public High Schools $1-18$} \\
\hline & & 1 & 2 & 3 & 4 & 5 & 6 & 7 & 8 & 9 & 10 & 11 & 12 & 13 & 14 & 15 & 16 & 17 & 18 \\
\hline $\begin{array}{l}\text { Percentage of students } \\
\text { who live in low-income } \\
\text { households }\end{array}$ & 16.9 & 24 & 29 & 13 & 27 & 36 & 10 & 23 & 13 & 11 & 23 & 22 & 11 & 18 & 20 & 20 & 22 & 12 & N/A \\
\hline $\begin{array}{l}\text { Percentage of students } \\
\text { whose parents have some } \\
\text { university education }\end{array}$ & 35.6 & 26 & 20 & 21 & 21 & 17 & 40 & 19 & 25 & 26 & 21 & 20 & 37 & 17 & 24 & 23 & 31 & 25 & N/A \\
\hline $\begin{array}{l}\text { Percentage of students } \\
\text { who receive special } \\
\text { education services }\end{array}$ & 14.9 & 16 & 16.1 & 19.5 & 98.4 & 13 & 15.1 & 5.6 & 13.4 & 24.8 & N/A & 3.3 & 7.6 & 17.1 & 12.8 & 21.6 & 17.3 & 19.2 & N/A \\
\hline $\begin{array}{l}\text { Percentage of students } \\
\text { identified as gifted }\end{array}$ & 1.4 & 0.7 & N/A & N/A & N/A & N/A & N/A & 0.5 & 0.3 & N/A & N/A & N/A & 2.9 & N/A & 0.4 & 0.4 & N/A & N/A & N/A \\
\hline $\begin{array}{l}\text { Percentage of students } \\
\text { whose first language is } \\
\text { not English }\end{array}$ & 23.9 & 20.9 & 48.3 & 6.7 & 5.3 & 55.1 & 13.9 & 24.6 & 18.6 & 15.2 & 3.9 & 13.8 & 43.3 & 8.6 & 6 & 9.4 & 84.6 & 41.8 & N/A \\
\hline $\begin{array}{l}\text { Percentage of students } \\
\text { whose first language is } \\
\text { not French }\end{array}$ & 96.7 & 99.5 & 100 & 99.9 & 100 & 98.6 & 99.3 & 100 & 99.9 & 99.3 & 100 & 99.5 & 99.2 & 99.3 & 99.9 & 99.2 & 80.8 & 70.1 & N/A \\
\hline $\begin{array}{l}\text { Percentage of students } \\
\text { who are new to Canada } \\
\text { from a non-English } \\
\text { speaking country }\end{array}$ & 3.0 & 1.5 & 24.5 & 0.7 & 0.3 & 29.7 & 0.7 & 1.0 & 0.6 & 0.6 & N/A & 3 & 2.8 & 0.2 & 0.8 & N/A & 13.5 & 2.7 & N/A \\
\hline $\begin{array}{l}\text { Percentage of students } \\
\text { who are new to Canada } \\
\text { from a non-French- } \\
\text { speaking country }\end{array}$ & 3.1 & 1.8 & 23.1 & 0.9 & 0.5 & 26.8 & 0.6 & 1.0 & 0.7 & 0.7 & N/A & 2.7 & 2.8 & 0.5 & 1.0 & 0.4 & N/A & 1.4 & N/A \\
\hline
\end{tabular}

${ }^{\mathrm{a}}$ Moved to Canada within the last three years from a country other than Australia, Great Britain, Ireland, New Zealand, or the United States. ${ }^{b}$ Moved to Canada within the last three years from a country other than Belgium, Benin, Bulgaria, Burkina Faso, Burundi, Cambodia, Cameroon, Cape Verde, Central African Republic, Chad, Comoros, Congo, Democratic Republic of the Congo, Cote d'Ivoire, Djibouti, Dominica, Egypt, Equatorial Guinea, France, Gabon, Guinea, Guinea-Bissau, Haiti, Laos, Lebanon, Luxembourg, Madagascar, Mali, Mauritania, Mauritius, Republic of Moldova, Monaco, Morocco, Niger, Romania, Rwanda, Sao Tome and Principe, Senegal, Seychelles, St. Lucia, Switzerland, Togo, Trinidad and Tobago, Vanuatu or Vietnam. 
Table 1 demonstrates the differentiation of student populations in the city's high schools. The table data were drawn from the Ontario Ministry of Education's School Information Finder: http://www.edu.gov.on.ca/eng/sift/. Two local English-speaking high schools play a key role in the settlement and social inclusion of immigrant and refugee youth. In relation to other schools in the city, these two schools (schools 2 and 5 in the table) have among the highest percentage of students who live in low-income households and among the lowest percentage of students whose parents have some university education - two widely used indicators of social class. A major difference remains the "newness" of the school population, as recent immigrants are largely concentrated into these two high schools. The overview in Table 1 suggests both the spatialization and concentration of poor, racialized, and newcomer youth into particular schools. The social significance and effects of this concentration on immigrant and refugee youth identity will be explored later in the paper.

When immigrant and refugee youth arrive, they are placed into one of three academic streams based on an assessment of their educational levels: English language development (ELD), English as a second language (ESL), and "regular" or "mainstream" programs. ELD programs specifically target students with significant gaps in their previous education and those who speak very little or no English. These students require intensive specialized literacy and English language instruction. The ESL program is designed primarily for students who have received a steady and consistent education but require English language instruction. In high school, both ELD and ESL programs have five levels, A through E. When students are in the first two levels (A and B), they are typically placed in "sheltered classrooms" in combination with some regular non-academic classes such as art, physical education, and drama. Sheltered classes allow for intensive targeted language instruction. Participation in these select mainstream classes provides additional social engagement opportunities. When students enter the C, D, and E levels, they begin to take more regular academic or non-academic classes. By Level E students usually take only one ELD or ESL course and are enrolled in regular classes.

Regular courses offer three streams: applied, academic, and essential. Students who graduate from the ELD program typically enter either the applied or the essential stream, while students who graduate from the ESL program typically enter the applied or the academic stream. Students who complete essential-level courses are awarded a certificate of completion and move directly into the workforce upon completion of their studies. In addition to the English language and development curriculum, the schools in our study offer various supplemental services and programs that assist immigrant newcomer youth, such as free breakfast and lunch programs and transportation vouchers. These schools also have partnerships with Settlement Workers in School, a program funded by Citizenship and Immigration Canada that places trained settlement workers into schools in order to provide a direct point of access to various settlement services for young immigrants and their families. 
International Journal of Child, Youth and Family Studies (2017) 8(2): 90-109

\section{Overview of the Study}

This paper draws on focus group and interview data collected as part of a larger study that examined the migration, settlement, and social inclusion experiences of immigrant and refugee youth living in the city (Selimos, 2017). The research study included three focus groups with a total of 35 newcomer youth and 30 in-depth interviews with newcomer youth; a total of 65 youth $(\mathrm{M}=30, \mathrm{~F}=35)$ participated in the study. There were also 18 interviews with teachers and social workers who work closely with immigrant youth living in the city.

Participants in the three focus groups were recruited through local settlement agencies. They were between 16 and 22 years of age, with 17 males and 18 females. During these group conversations, participants were asked to discuss a series of questions that explored their migration and settlement experiences with particular attention to their schooling experiences. Participants were also asked to comment on the challenges they faced coming to live in a new country and a new city with respect to various spheres of their lives, including family, school, peer relations, and community.

The 30 newcomer youth interview participants were recruited through a local high school and through various settlement agencies in the city. Interview participants ranged from 16 to 22 years of age. Thirteen males and 17 females participated in the interviews. Semi-structured interviews sought to generate insights into the personal stories of migration and to understand how youth participants made sense of and experienced their migration, settlement, and social inclusion in Canada. In particular, interview participants were asked to reflect on their premigration lives and their current lives in Canada, including their experiences with schools and their future aspirations and goals. Topics of discussion included their families, friends and peers, schools, neighbourhoods, employment experiences, and their overall impressions of the city.

In addition to focus groups and interviews with immigrant and refugee youth, interviews with 15 teachers and 3 youth settlement workers were conducted. Although we do not feature their voices prominently in this paper, we used these interviews primarily as "factual interviews" (Kvale \& Brinkmann, 2009, p. 150) in order to gain a contextual understanding of the range and the types of services and educational programs available to young immigrants and refugees in the city.

Most newcomer youth participants had lived in Canada for less than five years. Their countries of descent were diverse, including Iraq, Congo, Somalia, Ethiopia, Albania, Guinea, Haiti, Eritrea, China, Lebanon, Sudan, Liberia, Russia, Jordan, Haiti, Burundi, El Salvador, the Dominican Republic, and the Philippines. Forty percent of the participants arrived as refugees; the remainder entered Canada through family sponsorship programs or as dependents of parents who immigrated to Canada through the skilled workers program. There was considerable variation in the size and composition of their families in Canada: with parents, in a one-parent household, without parents, with relatives, and in a large family with many siblings. Some had parents who were highly educated professionals or who came from, as one participant remarked, "distinguished 
families" in their countries of origin. Others had parents with limited university education who had worked in non-professional fields or were small business owners in their home countries. Many of the participants' parents were attending English courses and were either looking for work or, if already working, looking for more reliable, full-time employment, suggesting a significant degree of financial insecurity.

All interviews and focus groups were conducted in English. The resulting data were transcribed, and analyzed according to themes that produced insights into participants' migration and settlement experiences. The analysis provided in this paper focuses specifically on participants' experiences of education and schooling pertaining to the three guiding questions listed above. In order to protect the anonymity of research participants, all names used in this paper are pseudonyms, and any information that could be used to identify the participant has been removed or altered.

\section{Findings}

Participants consistently framed Canada as a place of opportunity and stressed education as the central arena in which their dreams and desires for a better life could be fulfilled. They spoke of their desire to achieve academic success, their high educational aspirations, and their strong valuation of education (Krahn \& Taylor, 2005), insights that align with other scholars who have suggested that the very decision to migrate "is indicative of a 'goal directed' activity that is centered on working actively toward improving familial life chances, which will in itself be reflected in positive orientations and work effort in school" (Devine, 2011, p. 136-137).

Overall, our findings point to how the everyday practices and social organization of schooling produce contradictory effects on newcomer youths' sense of themselves, their aspirations, and their feelings of inclusion and belonging. In order to demonstrate these simultaneous and contradictory processes, we examine (a) the manner in which participants' spoke about the position of their schools within the larger community, (b) the nature of peer relations among students within their schools, and (c) the complex relationships participants forged with school officials, focusing particularly on teachers.

\section{Schools as Sites of Belonging and Stigmatization}

Newcomer youth identified their schools not just as places of learning, but as central sites of their settlement, social inclusion, and belonging. It was at school that they learned English and learned about the community and larger Canadian society, and they appreciated the supports they received in these schools. Tahir, 19, originally from Iraq, summed up a general feeling among many participants when he declared:

I think it's a place. They gave me like experience. It's the place that taught everything about, I don't want to say the outside world, but it's a place that taught me mostly everything. How to interact with people, how to make friendships... 
High school for me in Canada was beyond just getting lessons and marks... Like they teach you things that are not in the books.... I would say they teach you to be involved in the community.

Perhaps because of these supports, newcomer youth developed deep attachments to their schools and it was common for participants to describe their school as a second "home" that "helps a lot" and "feels like a family." Many spent most of their days at school, arriving early to study or socialize and staying late to be with friends or participate in extracurricular activities. The multicultural nature of their schools and the presence of other immigrant youth were highlighted as features that made participants feel a sense of comfort and belonging. Participants saw themselves reflected in the peers around them and felt that fellow students and some school officials shared an understanding of the problems and pressures they faced. School was a place where "everybody was from somewhere else" and where cultural differences were accepted as a normal feature of everyday life. Aniso, 19, a refugee from Somalia who had lived in Canada for nearly five years, expressed the common feeling of belonging that resulted from the presence of many other immigrants in her school:

When I am with people from all around the world, I don't know it's just, I don't know how to describe, it's just a feeling that I get, it just makes me, automatically I feel comfortable around with them.

Multicultural celebrations, hallways decorated with flags and maps from around the world, and citizenship ceremonies contributed to a feeling that their schools were international places that valued diversity.

Although participants took tremendous pride in the multicultural nature of their schools, many also recognized that their schools were somehow different from other high schools in the city. As several teachers suggested, "to be different is to be normal here", and "to be the minority is to be in the majority" - sentiments often reiterated by the young people interviewed. In fact, throughout the interviews and focus groups, newcomer youth referred to their high schools as the "multicultural schools" while the other high schools were where "Canadians" go. Although this perception ignores the complex social and cultural diversities characterizing other schools in the city, as well as the presence of long-term residents and Canadian-born youth in the "multicultural schools", it highlights a common perspective amongst both staff members and immigrant youth that their schools were somehow "marked off” from mainstream Canadian schools.

Many teachers and newcomer youth, especially those who had lived long enough in Canada to become aquainted with the larger community, were sensitive to negative stereotypes surrounding their schools. Their schools were often seen as poor, non-academic, drug-riddled, and violent. Such characterizations mixed classist, xenophobic, and racialized discourses with stereotypes about the particular ethnic and racial groups that attended these schools. Participants shared with me some of the nicknames others in the community had for their schools: "Welfare 
International Journal of Child, Youth and Family Studies (2017) 8(2): 90-109

High", "Little Mogadishu", and "Terrorist High". As one teacher who had worked in one of the immigrant-receiving schools for over 30 years commented:

We get stuff when we go to other schools. You know people cheer, "They will blow-up your house!" Just this year we had one of our kids, a basketball player, he was a tall skinny kid, and they started cheering, "He's hungry, he's hungry, he's hungry!" You know, ridiculing the kid.... Or we go to games and they cheer "E-SL, E-S-L. What do our kids do [in response]? S-T-Ds, S-T-Ds. So we get that crap.

"People assume things from the outside," another teacher told me. "They hear the stories that there are gangs and all that stuff going on in our building." One youth participant noted that people "look at the school as a place [that is] academically poor, a place where all disputes and fights take place." He continued,

They always try to find the bad things within the school. That's what I'm looking for. While other schools that have bad things too, they don't focus on the bad things that happen in other schools... I actually don't have an answer for that. I have no idea. ... Maybe, just because they are immigrants. You know what I mean? So it's that would make a difference.

School stigmatization shaped how youth understood themselves and their place in the larger community. For one season, the first author assisted in coaching soccer teams at one of the "immigrant-receiving" schools. The following conversation was documented after our team lost a match that was perceived by the players to be poorly and unfairly officiated:

Player: They always treat us like this. They hate us."

Author: What do you mean they hate you?

Player: They hate [our school].

Author: Why do they hate [the school]?

Player: Because we're multicultural.

Participants responded to these stereotypes by asserting that all schools have problems and that, in fact, their schools were much safer and had much less of a drug-use problem than many of the other schools in the city. Immigrant and refugee youth suggested that they were much more appreciative of teachers and the educational opportunities that were available to them than were Canadian students, who in their opinion were more likely to feel a sense of entitlement, and be disrespectful and unappreciative of teachers.

Although most students were not interested in leaving their schools, some transferred or attempted to transfer to other schools in the city after completing their language courses. This was usually because those other schools were closer to their homes or because they believed that those 
other schools offered more advanced academic courses, which they thought would better improve their chances of attending university. Participants had varying experiences of transferring from their "multicultural schools" to these "Canadian" schools. Gideon, for instance, contrasted the diversity of his old school to his new school in the city, framing his experience primarily as an opportunity to learn about Canadian culture:

[My old school] was very different because it was like everyone was from all over the world. So I got to learn a lot about different cultures... But at [my new school], it feels like everyone is the same. It's mostly like one culture, like Canadian people. At [name of school] you actually learn more about Canada, which is good for me because I really lack a lot of stuff about Canada.

Amina, on the other hand, relayed the negative experience she faced when she attempted to register at another school in the city:

I am not in ESL anymore... I went there. I gave all my papers and [the principal] looked at me in a dirty look way, because I wear hijab. My level of English, honestly, it's not that good. I know that. I have an accent. [Mocking the voice of the principal]: "In here, we have to measure the language of how you speak and how you read. Our students, they have a really high-speaking English." I know what was meant: "I don't think you should be here." ... Actually it was my dream school. ... There it's like the same thing as college. What you're taking, it's really hard. ... I was dreaming about it even, honestly. But what [the principal] said ruined my day. I even cried. I just walked away.

Moti shared a similar experience:

I went by myself and then [they] saw my mother with the hijab ... [The principal] is smiling at me like this and then sees my mom walking from the back. [Their] face changes. ... Right away, I knew that [they] wouldn't accept me. ... So you just deal with it and go back to your school.

In sum, participants developed strong attachments to their schools, both a strong sentiment of school belonging related to the support they received, and the solidarity emerging from the presence of other immigrants, co-ethnics, or people from similar regions in the world. Simultaneously, however, the concentration of newcomer immigrant and refugee youth into particular schools reproduced categories of "mainstream" and "other", a division which participants incorporated into how they spoke of their schools and themselves.

\section{Peer Relations in School: Complex Inclusions and Exclusions}

The concentration of newcomer youth in specific schools in the community, as well as the daily structure of school life, which for many included targeted EDL or ESL instruction, shaped the everyday interactional opportunities for newcomer youth. Newcomer youth tended to develop 
friendships with other newcomer youth, often across different cultural or linguistic backgrounds. Friendships formed around "shared tastes" (Harris, 2013, p. 42-45) in school matters, music, film, sport, or fashion, and the common experience of migration and settlement. Participants noted the normality of routine intercultural encounters and highlighted the high levels of civility and appreciation for cultural differences, especially in their English language learning classes. Many told stories of how they supported each other in school by helping with homework, re-explaining assignments, and providing each other with information about the school system and the larger community.

However, some suggested that outside of structured school activities, as Joseph put it, "kids want to hang out with their own kind. Arabs want to hang out with the Arabs. Mexicans want to hang out with the Mexicans." Recent immigrants were more likely to "hang out" with their own ethnocultural groups or with students who shared similar cultural, religious, or regional affiliations; this effect may be due to a natural tendency to seek comfort in the company of those who share cultural or linguistic similarities, especially in the early period of settlement. Often, these young people were not judged negatively by their immigrant peers, as many could empathize with the feeling of seeking comfort in people who shared a similar background. Some identified strong social pressure to hang out with peers from their ethnocultural background. They told stories of being teased, gossiped about, or criticized on occasions when they sought to make friends with other peers. In some cases, these interactions impacted their desire to build friendships outside of their ethnocultural group. Others said that they distanced themselves from people of their own cultural or linguistic background, actively seeking friends among those who did not share it. They found their co-ethnic peers "gossipy", judgmental, and jealous.

Participants reported that intercultural conflicts among newcomer youth were quite rare. When conflicts did occur, participants often downplayed the role of interethnic hostilities and usually explained these events as the result of personal disagreements. However, some participants did speak of being the target of racial name calling from other immigrant students. For example, Michael, originally from Ethiopia, experienced several months of racialized teasing from a group of immigrant peers after first arriving in Canada. However, as he established himself as a willing student and connected with these peers over a mutual interest in basketball, they became his friends. This narrative suggests that racialized teasing may be experienced more acutely during the "first phase of strangeness and adaptation" (Sedano, 2012) and fade as common bonds are formed and as new students enter into peer culture.

Close friendships between newcomer youth and Canadian-born youth were relatively uncommon. Participants cited a range of reasons for this phenomenon. First, they highlighted the lack of opportunities to interact with Canadian-born or long-term residents given that most of their school time was spent in EDL and ESL courses. It was only after they successfully transferred out of these courses into a regular stream that they had more opportunities to interact and build friendships. Second, lack of English language skills and a lack of confidence in their communication skills meant some felt too intimidated and embarrassed to approach "Canadian" 
students. They worried about being teased or criticized for linguistic errors. Third, "Canadian" students belonged to already established, close-knit groups that often stretched back to grade school. These groups had formed around identities, interests, and norms and were not necessarily open to new members. As Wahid, 21, reported:

See the thing is you would see Arabs who were born here and they are friends with Canadians, like white people who were born here. It's mostly like the people who are born here, as a group, and then the people who were not born here is another group. I think it's an obvious reason. Most people you see at [school], they come from the same grade school. It's your grade school friends who come out with you to grade nine. They attended grade school and they would obviously hang out together rather than hang out with someone new.

Some participants were wary of getting too close to certain long-term resident or Canadian-born youth, including those who shared a similar ethnic or racial background. They took issue with certain behaviours they thought were characteristic of these youth, such as being disrespectful to teachers, doing drugs, drinking alcohol, swearing, or being sexually permissive. A few spoke of racist slurs or xenophobic comments made by Canadian youth toward them, such as being told they were terrorists, to take off their hijabs, or to "go back to the jungle". Although most saw these racist insults as the actions of a few "bad apples" — reaffirming that they believed Canadians were "very nice" - these incidents did have the effect of qualifying with whom they wished to become friends.

Some participants succeeded in forging friendships with Canadian-born or long-term resident youth. In many cases, this was a result of a Canadian peer reaching out and introducing himself or herself, and typically this friendship formed after several years of living in Canada. Often, such friendships formed when newcomer youth transitioned from English language learning classes into mainstream courses. Participants also formed friendships with long-term resident youth through participation in extracurricular or leisure activities, especially team sports. Participation in these activities encouraged interaction and provided a common interest around which friendships could form.

In summary, participants typically divided their discussion of friendships between, on the one hand, their relationships with other newcomer youth and, on the other hand, the nature of social relationships between them and Canadian-born or long-term resident youth. This is perhaps not surprising given that the daily structure of educational spaces limited opportunities to interact with Canadian-born or long-term resident youth, so most developed friendships with other newcomer immigrant peers, often across complex social and cultural differences. These friends understood each other's struggles; the common experience of migration and settlement was a central feature of their collective bonds. Furthermore, the perceived exclusiveness of alreadyexisting peer groups made it difficult for immigrant and refugee youth to forge friendships with Canadian-born or long-term resident youth. For some, experiences of racism, xenophobia, and 
International Journal of Child, Youth and Family Studies (2017) 8(2): 90-109

Islamophobia were felt as direct threats to one's reputation and sense of self. In response, immigrant and refugee youth searched for friends who provided a safe environment, and this sometimes meant selecting friends who were socially and culturally similar.

\section{Student-Teacher Relationships: Providing Support and Reproducing Dependencies}

The majority of participants viewed mastering English and achieving English fluency as the most important step towards"making a life" in Canada and being able to assist one's family in the daily activities of life outside school. Given the high priority of English language learning among participants, it is not surprising that many participants spoke highly of the English language supports they received at school, particularly the close relationships they developed with their English language teachers, often identifying by name the teachers who really "helped them out". In fact, it was common for participants to speak about how they "loved" certain English language teachers and considered some of them to be like second mothers or fathers. As Aniso said, "Teachers are like my family" who "tell me what Canada is". In addition to teaching newcomers "the gift of language," as one participant remarked, English language teachers represented for many the key source of information about Canada, and a critical node of care and support during their initial, difficult transition to Canadian society. Ayaan, 18, originally from Somalia, expanded on this point:

When I came here I wasn't knowing the language.... If I need to talk [to] someone, a student bullying me, I would always go and talk to my teachers. They help me, and they were always telling me what Canada is. How people is. They teach me a lot about Canada. So, I would say [my school] was part of my life being in Canada.

Participants also commented on the "extra help" many teachers provided, which included assisting students after school with homework, providing assistance with filling out various application forms, discussing future career plans, attending sporting events, giving advice, supervising afterschool clubs, providing rides home (especially in the winter months), and even giving young people money to buy lunch, school supplies, or a bus ticket.

However, participants also spoke about the ways teachers and school practices discouraged, thwarted, and limited their aspirations. Many spoke of feeling that some teachers treated them in ways that communicated they were somehow less intelligent than Canadian-born or long-term resident youth. The impact of teacher judgements was particularly salient when participants spoke about course placements. Some participants reported feeling that they were unfairly placed by school officials into course streams below their perceived abilities and in contrast to their academic and career goals. This issue related to placement in English language learning courses (ELD vs. ESL), as well as content-area courses such as mathematics and the sciences. Furthermore, in cases where some newcomer youth felt they were placed in courses below their competencies or wishes, many found it difficult to convince school officials to switch them out of those courses, especially those who did not have family members or adults who could 
advocate on their behalf. Immigrant youth were particularly upset about being streamed into nonacademic classes because they knew that to achieve their high educational aspirations, they needed to be in academic classes.

Analysis of interview and focus group data suggests that racialized youth were more likely to remark on issues of course placement. Samuel, a refugee from the Democratic Republic of the Congo, told a long story of being placed in an applied mathematics course, despite the fact that he felt he had sufficient grades to be placed in a more advanced class. Despite meeting with his teachers and expressing his concerns, he was unable to transfer out of the class and is now trying to upgrade his courses through distance education. Other participants shared stories of being told that their expectations were too high and that they should aim to become plumbers or welders. Moti, originally from Ethiopia, observed, "all the people who come from Africa, they put them in ELD. The people who come from European countries who don't speak English goes to ESL." Amina, originally from Somalia, told us that her friend and her sister were both placed into workplace English even though her sister "passed with 80 in her ESL" and that she "should go to academic or applied classes." She stated that the experience was very disheartening: "They started crying, you know, [because it meant] you can't go to college until you're 21."

In sum, newcomer youth juxtaposed the benevolence and support they received from teachers with school practices and attitudes that thwarted or blocked their future prospects. Teachers were sources of critical support and guidance, but their decisions also helped reproduce newcomer youths' dependencies in ways that limited their social pathways. In the context of our research, racialized youth were more likely to identify course placements as an issue of significant concern.

\section{Discussion}

This study foregrounds a complex picture of the myriad ways in which schools shape the social inclusion of newcomer youth. The study offers three important insights that show how schools function simultaneously as sites of inclusion and exclusion in ways that produce ambivalence in newcomer youth with respect to their sense of social inclusion and belonging.

First, the concentration of newcomer youth into particular schools marked them out from other youth populations in ways that reproduced categories of "mainstream" and "other". Although other schools in the city are diverse in terms of the social, cultural, and economic background of the students and staff, the participants in this study understood their schools to be the "multicultural schools" while other schools were where "ordinary Canadians" go. Participants incorporated this distinction - this sense of "being other" — into how they spoke of their schools and themselves. Within this context of school differentiation, participants developed strong attachments to their respective schools. This sense of belonging related to the social and cultural recognition they received in their schools and the solidarity emerging from the presence of other immigrants, co- 
ethnics, or people from similar regions in the world; it was also perhaps a reaction to the stigmatization of their schools within the larger community.

Second, within the immigrant-receiving schools, the daily structure of educational programs limited newcomer youth's opportunities to interact with Canadian-born or long-term resident youth. Most developed friendships with other newcomer peers, often across complex social and cultural differences, by bonding over the common experience of being a newcomer immigrant. While their sense of being a newcomer certainly influenced these friendship dynamics, other factors also shaped with whom newcomer youth formed friendships. The perceived exclusiveness of established peer groups made it difficult for newcomer youth to forge friendships with Canadian-born or long-term resident youth. Moreover, linguistic insecurity, the fear of being teased or humiliated, and concerns over experiences of racism, xenophobia, and Islamophobia further limited interactions. In order to avoid humiliation or embarrassment, some chose friends who would provide a safe environment, which sometimes meant selecting friends who were socially and culturally similar. What emerges are complex peer group inclusions and exclusions that produce feelings of support, inclusion, and belonging, as well as stigmatization and marginality.

Third, participants consistently formed positive relationships with their teachers, especially with their English language teachers. However, several racialized newcomer youth also commented passionately on the effects of low expectations on their self-confidence and sense of future opportunity. These findings corroborate previous research showing that racialized minority youth, immigrant or not, are often stereotyped by school officials in ways that shape and limit their educational experiences and opportunities (Dei, Mazzuca, McIsaac, \& Zine, 1997). Krahn and Taylor (n.d.) noted inconsistent findings in statistical research regarding course streaming, with some studies indicating that immigrant youth can be disproportionately found in educational streams that would restrict their educational options, while other studies suggest that these young people are encouraged to "aim high". While this qualitative research study cannot demonstrate the frequency of these reported phenomena, it demonstrates that issues of low expectations among teachers remain a recurrent and passionate topic of concern among many newcomer youth.

\section{Limitations}

We would like to draw attention to the fact that we did not use translators, primarily due to budget restrictions. Hence, acceptable English proficiency was an important selection criterion for interview and focus group participation; immigrant youth who lacked English abilities could not be included. The young people who participated in this study also attended English-speaking high schools in the city. The city has a relatively substantial French-speaking immigrant population, and some young French-speaking immigrant youth attend French-speaking high schools in the city. The social inclusion experiences of these newcomers is an important area of future inquiry. Gender and race/ethnicity emerged as important factors shaping young immigrants' migration and

settlement experiences, including their schooling experiences. Although this study identified the 
complexity and heterogeneity of participants' experiences, it did not provide a detailed gender or race analysis. How, for example, do gender and race shape how newcomer youth experience schooling, peer groups, and community life? These important questions deserve heightened attention in future research.

\section{Conclusion}

What then are the policy and practical implications that we offer as a result of this study, which has emphasized through youth narratives the complexities of how schools shape newcomer youth inclusion and exclusion? Educational policymakers and practitioners at all levels must comprehend and be willing to deal with the complexity of the factors that come into play as they create and implement programs and practices geared to the settlement and social inclusion of newcomer youth. The first practical implication of this study is that robust educational supports and services for initial settlement needs such as language learning are, according to newcomer youth themselves, appreciated and highly welcome. Youth narratives confirmed the effectiveness of these supports and point to the important role they play in their lives. Educational practitioners and other community stakeholders interested in supporting the social inclusion of newcomer youth should develop and implement ESL and ELD programs and ensure adequate funding of these essential programs.

While educational supports for initial settlement needs are essential, attention should also be paid to the long-term inclusion of newcomer youth. It is a major challenge for communities to create practical approaches that do not contribute to social segregation or limit the social pathways of newcomer youth. While the challenges identified in this paper are not unique to the site of the research study, these complexities play out within the unique social, cultural, economic, and institutional arrangements that characterize the host communities. Educational practitioners should

critically examine how extant structures create both inclusionary and exclusionary practices and seek a synthesis of ideas among various stakeholders, including youth, teachers, administrators, and those within the larger community who are interested in the well-being of newcomer youth. There is a need for collaborative, dialogical practices that provide all relevant stakeholders, including newcomer youth themselves, opportunities to come together to create new possibilities of understanding and cooperative action. Educational practitioners must join together collaboratively with young people and interested stakeholders within the community to create opportunities and mechanisms for ongoing dialogue and action. 
International Journal of Child, Youth and Family Studies (2017) 8(2): 90-109

\section{References}

Anisef, P., \& Kilbride, K. M. (Eds.). (2003). Managing two worlds: The experiences and concerns of immigrant youth in Ontario. Toronto, ON: Canadian Scholars' Press.

Brewers, C. A., \& McCabe, M. (2014). Immigrant and refugee students in Canada. Edmonton, AB: Brush Education.

Davis, J. M., \& Hill, M. (2006). Introduction. In E. K. M. Tisdall, J. M. Davis, M. Hill, \& A. Prout (Eds.), Children, young people and social inclusion: Participation for what? (pp. 120). Bristol, United Kingdom: The Policy Press.

Dei, G., Mazzuca, J., McIsaac, E., \& Zine, J. (1997). Reconstructing 'dropout': A critical ethnography of the dynamics of black students' disengagement from school. Toronto, ON: University of Toronto Press.

Devine, D. (2011). Immigration and schooling in the Republic of Ireland: Making a difference?. Manchester, United Kingdom: Manchester University Press.

Fangen, K., Johansson, T., \& Hammaren, N. (2012). Young migrants: Exclusion and belonging in Europe. Chippenham and Eastbourne, United Kingdom: Palgrave MacMillan.

Francis, J., \& Yan, M. C. (2016). Bridging the gaps: Access to formal support services among young African immigrants and refugees in metro Vancouver. Canadian Ethnic Studies/Etudes Ethniques au Canada, 48(1), 77-100. doi:10.1353/ces.2016.0010

Garnett, B., Adamuti-Trache, M., \& Ungerleider, C. (2008). The academic mobility of students for whom English is not a first language: The roles of ethnicity, language, and class. The Alberta Journal of Educational Research, 54(3), 309-326.

George, G., Selimos, E. D., \& Ku, J. (2017). Welcoming initiatives and immigrant attachment: The case of Windsor. Journal of International Migration and Integration, 18(1), 29-45. doi:10.1007/s12134-015-0463-8

Hall, K. D. (2002). Lives in translation: Sikh youth as British citizens. Philadelphia, PA: University of Pennsylvania Press.

Harris, A. (2013). Young people and everyday multiculturalism. New York, NY: Routledge.

Hebert, Y., Sun, X. S., \& Kwoch, E. (2004). Focusing on children and youth: The role of social capital in educational outcomes in the context of immigration and diversity. Journal of International Migration and Integration, 5(2), 229-249.

Kanu, Y. (2008). Educational needs and barriers for African refugee students in Manitoba. Canadian Journal of Education, 31(4), 915-940. 
International Journal of Child, Youth and Family Studies (2017) 8(2): 90-109

Krahn, H., \& Taylor, A. (n.d.). "Streaming" in the 10th grade in four Canadian provinces in 2000. Retrieved from www.statcan.gc.ca/pub/81-004-x/2007002/9994-eng.htm

Krahn, H., \& Taylor, A. (2005). Resilient teenagers: Explaining the high educational aspirations of visible-minority youth in Canada. Journal of International Migration and Integration, 6(3-4), 405-434. doi:10.1007/s12134-005-1020-7

Kvale, S., \& Brinkmann, S. (2009). InterViews: Learning the craft of qualitative research interviewing. Thousand Oaks, CA: Sage Publications Inc.

Lave, J., \& Wenger, E. (1991). Situated learning: Legitimate peripheral participation. Cambridge, NY: Cambridge University Press.

Lauer, S., Wilkinson, L., Yan, M. C., Sin, R., \& Ka Tat Tsang, A. (2012). Immigrant youth and employment: Lessons learned from the analysis of LSIC and 82 lived stories. Journal of International Migration and Integration, 13, 1-19. doi:10.1007/s12134-011-0189-1

LeVasseur, L. (2008). The social function of the school and the work performed by Montreal teachers in the context of Quebec student integration policies. In D. Gerin-Lajoie (Ed.), Educators' discourses on student diversity in Canada: Context, policy, and practice (pp. 133-162). Toronto, ON: Canadian Scholars' Press.

McKenney, K. S., Pepler, D., Craig, W., \& Connolly, J. (2006). Peer victimization and psychosocial adjustment: The experiences of Canadian immigrant youth. Electronic Journal of Research in Educational Psychology, 4(2), 239-264.

Murphy, J. (2010). The settlement and integration needs of immigrants: A literature review. Ottawa, ON: The Ottawa Local Immigration Partnership. Retrieved from http://olipplio.ca/knowledge-base/wp-content/uploads/2013/03/Olip-Review-of-Literature-FinalEN.pdf

Ngo, H. V. (2009). Patchwork, sidelining and marginalization: Services for immigrant youth. Journal of Immigrants and Refugees Studies, 7, 82-100. doi:10.1080/15562940802687280

Ngo, H. V., \& Schleifer, B. (2005). Immigrant children and youth in focus. Canadian Issues, spring, 29-33.

Sedano, L. J. (2012). On the irrelevance of ethnicity in children's organization of their social world. Childhood, 19(3), 375-388. doi:10.1177/0907568212445226

Selimos, E. D. (2017). Young immigrant lives: A study of the migration and settlement experiences of immigrant and refugee youth in Windsor, Ontario (Unpublished doctoral dissertation). University of Windsor, Windsor, Ontario. 
International Journal of Child, Youth and Family Studies (2017) 8(2): 90-109

Shahsiah, S. (2006). Identity, identification, and racialisation: Immigrant youth in the Canadian context (Major research paper). Retrieved from Ryerson University Digital Commons. http://digital.library.ryerson.ca/islandora/object/RULA\%3A748/datastream/OBJ/view

Silver, H. (2007). Social exclusion: Comparative analysis of Europe and Middle Eastern Youth (Middle East Youth Initiative Working Paper). Wolfensohn Center for Development, Washington, DC, and the Dubai School of Government, United Arab Emirates.

Sweet, R., Anisef, P., \& Walters, D. (2010). Immigrant parents' investments in their children's post-secondary education. Canadian Journal of Higher Education, 40(3), 50-80.

Taylor, A., \& Krahn, H. (2013). Living through our children: Exploring the educational and career 'choices' of racialized immigrant youth in Canada. Journal of Youth Studies, 16(8), 1000-1021. doi:10.1080/13676261.2013.772575

Tomic, P. (2013). The color of language: Accent, devaluation and resistance in Latin American immigrant lives in Canada. Canadian Ethnic Studies, 43(1-2), 1-21. doi:10.1353/ces.2013.0018

United Nations Educational, Scientific, and Cultural Organization. (2016). Cities welcoming refugees and migrants: Enhancing effective urban governance in the age of migration. Paris, France: Author. Retrieved from http://unesdoc.unesco.org/Ulis/cgi$\underline{\text { bin/ulis.pl?catno }=246558 \& \text { set }=00591 B 323 B \_2 \_451 \& g p=0 \& l i n=1 \& 11=1}$

Walsh, C. A., Este, D., Krieg, B., \& Giurgiu, B. (2011). Needs of refugee children in Canada: What can Roma refugee families tell us? Journal of Comparative Family Studies, 42(4), 599-613.

Wilkinson, L. (2002). Factors influencing the academic success of refugee youth in Canada. Journal of Youth Studies, 5(2), 173-193. doi:10.1080/13676260220134430

Wilkinson, L., Yan, M. C., Ka Tat Tsang, A., Sin, R., \& Lauer, S. (2011). The school-to-work transitions of newcomer youth in Canada. Canadian Ethnic Studies, 44(3), 29-44. doi:10.1353/ces.2013.0000

Willis, P. (1977). Learning to labour: How working class kids get working class jobs. New York, NY: Columbia University Press. 